\title{
Reproductive performance of prepubertal and pubertal heifers submitted to timed artificial insemination protocols
}

\begin{abstract}
This study investigated the effect of using estradiol cypionate (ECP) and equine chorionic gonadotropin (eCG) as part of a hormonal protocol for timed artificial insemination (TAI) on the pregnancy rate (PR) in prepubertal and pubertal Nellore heifers pretreated with intravaginal progesterone (P4).

Methods: Two groups of animals were assessed: prepubertal heifers (no corpus luteum $(\mathrm{CL})$ present and follicles $<8 \mathrm{~mm}$ diameter; $\mathrm{n}=130$ ) and pubertal heifers (CL present; $\mathrm{n}=94)$. The beef heifers weighed between $297-320 \mathrm{~kg}$ and body condition score was 2.3-3.5. On day $0(\mathrm{~d} 0)$, all heifers received an intravaginal device containing $0.558 \mathrm{~g}$ of $\mathrm{P} 4$, and $1.0 \mathrm{mg}$ of estradiol benzoate (EB). On d8, the $\mathrm{P} 4$ was removed and $0.075 \mathrm{mg}$ PGF $2 \alpha 300 \mathrm{IU}$ of eCG, and $2 \mathrm{mg}$ of ECP were administered. TAI was performed on day 10. Animals that return to show estrous signals post-TAI were re-inseminated (AI) $12 \mathrm{~h}$ after estrus observation. Animals that returned to estrus after conventional AI were kept with bulls for 45 days and after 30days, pregnancy diagnosis was performed.

Results: The PR in prepubertal and pubertal heifers were respectively for TAI $29.2 \%$ and $37.2 \%(\mathrm{p}>0.05)$; for conventional AI, $13.0 \%$ and $33.9 \%(\mathrm{P}<0.05)$; and for bulls breeding, $36.2 \%$ and $35.9 \%$, respectively. ( $\mathrm{P}>0.05)$. At the end of the breeding season, the $\mathrm{PR}$ in prepubertal and pubertal heifers was $60.7 \%$ and $73.4 \%(\mathrm{P}=0.062)$.

Conclusion: Use of the hormonal protocol was efficacious for both groups of animals due to the acceleration of puberty and this increased the PR at the beginning of the breeding season.
\end{abstract}

Keywords: bos indicus, nellore, timed-artificial insemination, breeding season
Volume 5 Issue 6 - 2017

\author{
Andre Luis Bastos de Souza,' Luiz Ernandes \\ Kozicki, ${ }^{2}$ Danilo Amadori Martins de \\ Oliveira, ${ }^{2}$ Romildo Romualdo Weiss, ${ }^{3}$ Melina \\ Andrea Formighieri Bertol, ${ }^{3}$ Ana Claudia \\ Machinski Rangel de Abreu, ${ }^{3}$ Rafaela Talini ${ }^{2}$ \\ 'VetMaxi Livestock Consulting Company, Brazil \\ ${ }^{2}$ School of Life Sciences, Pontifical Catholic University of Paraná, \\ Brazil \\ ${ }^{3}$ Department of Veterinary Science, Federal University of Parana, \\ Brazil
}

Correspondence: Luiz Ernandes Kozicki, School of Life Sciences, Pontifical Catholic University of Paraná - Brazil, Email kozicki.l@pucpr.br

Received: January 30, 2017 | Published: September 08, 2017
Abbreviations: TAI, timed artificial insemination; PR, pregnancy rate; $\mathrm{EB}$, estradiol benzoate; $\mathrm{P} 4$, progesterone; $\mathrm{ECG}$, equine chorionic gonadotrophin; PGF2 $\alpha$, prostaglandin F2 alpha; CL, corpus luteum; CEAU, commission of ethics for animal use; PD, pregnancy diagnosis; BS, breeding season; AI, artificial insemination; US, ultrasonography

\section{Introduction}

High numbers of prepubertal heifers at the beginning of the breeding season (BS) reduces reproductive efficiency in beef cattle. ${ }^{1}$ In Brazil, grazing Bos indicus heifers reach puberty between 22 and 36 months, and the age at first calving is between 44 and 48 months. ${ }^{2}$ Seasonality, poor pasture management, and poor nutrition during the heifer's growth phase are some of the variables that lead to the delayed onset of puberty in Bos indicus cattle. ${ }^{3}$ Studies have been conducted to induce puberty in heifers, using either nutritional management strategies, ${ }^{4}$ or intravaginal progesterone (P4) devices. ${ }^{5}$ Sales et al. induced prepubertal Bos indicus heifers by administering P4 with estradiol cypionate (ECP) after 10days. Silveira et al. ${ }^{5}$ used prepubertal and pubertal zebu heifers for timed artificial insemination (TAI). They found a higher pregnancy rate (PR) in the groups that had received P4 with estradiol benzoate (EB) and ECP compared to prepubertal heifers only exposed to bulls. The exposure of prepubertal heifers to P4 for 8days induced and synchronized estrus. Similar effects were observed by Wheaton et al. ${ }^{7}$ and Demeterco et al. ${ }^{8}$ Treatment with a P4 intravaginal device induced prepubertal heifers to cycle and also increased the uterine diameter ${ }^{6}$ even during anestrus. ${ }^{9}$ The addition of $\mathrm{EB}$ at the time of $\mathrm{P} 4$ removal potentiates this action. ${ }^{3}$

Peres et al. ${ }^{10}$ investigated the use of $\mathrm{P} 4$ intravaginal devices adding eCG at the time of P4 removal in Nellore heifers. SáFilho et al. ${ }^{3}$ used $400 \mathrm{IU}$ of eCG at the time of Norgestomet removal, achieving a PR of $50 \%$. In another study, the same researchers achieved a $48.2 \%$ PR, using ECP to induce ovulation after previous treatment with Norgestomet, and concluded that ECP can be successfully employed.

Rodrigues et al. ${ }^{11}$ used eCG and ECP after intravaginal P4 in prepubertal Nellore heifers. They observed an increase in the rate of estrus detection and ovulation, thus improving the PR earlier in the BS. Our group hypothesized that the administration of eCG and ECP to prepubertal and pubertal Bos indicus heifers, after P4 treatment and prostaglandin F2alpha (PGF2 $\alpha$ ) administration could lead to improvements in the PR of TAI.

The present study aimed to evaluate the efficacy of eCG and ECP to improve reproductive performance in prepubertal and pubertal Nellore heifers pretreated with intravaginal P4.

\section{Material and Methods}

This study was based on the principles of ethics in research involving animals, applicable in the country having consonance with the Commission of Ethics for Animal Use (CEAU). In this study, 224 (prepubertal and pubertal Nellore) heifers for commercial replacement 
were used. The animals were on average 25 months old (range, 24-27 months) and weighed an average of $312 \mathrm{~kg}$ (range, 297-320kg) with a body condition score (BCS) of $3.0(2.25-3.5 ; 1=$ thin to $5=$ obese). At the start of the study, $42.0 \%$ of the heifers were pubertal (presence of corpus luteum [CL] or follicles $>8 \mathrm{~mm}$ diameter) and $58.0 \%$ were prepubertal (absence of CLor follicles $>8 \mathrm{~mm}$ diameter). The animals grazed on Brachiaria brizantha and mineral salt and water were available ad libitum.

The experimental protocol for all animals is presented in Figure 1 , and was as follows: at day $0(\mathrm{~d} 0)$, a single-use intravaginal P4 device (0.558 g P4, Cronipres, Biogenesis Bagó, Curitiba-Brazil) was inserted as well as EB (1.0 mg, IM; Cronibest, Biogenesis Bago); on d8, P4 removal+PGF2á (Croniben, 0,075mg, IM, Biogenesis Bago)+eCG (300IU, IM; Folligon, MSD Animal Health, São Paulo)+ECP (Estradiol cypionate, 2mg, IM;E.C.P., Zoetis, Sao Paulo,
Brazil) were administered. On d10, TAI was performed using frozen semen. Ovarian ultrasonography (US) to evaluate CLs or follicles was performed on d45. Animals that were repeat breeders after TAI were re-inseminated using conventional AI (AI 10-12hours after estrus observation) and pregnancy diagnosis (PD) was performed 35 days later. Animals that came into estrus after AI were kept with bulls for 45 days. After 30 days with the bulls, ultrasound (Tringa model, Probe 5.0; Pyemedical Co., The Netherlands) was performed for PD.

\section{Statistical analysis}

To verify the difference between prepubertal and pubertal heifers the data corresponding to TAI, conventional artificial insemination (AI), and natural breeding were analyzed using ANOVA and the Fisher's tests; (P value lower than $<0.05$ was considered statistically significant). The statistical analysis was performed by means of GraphPad Prism Software, version 5.0

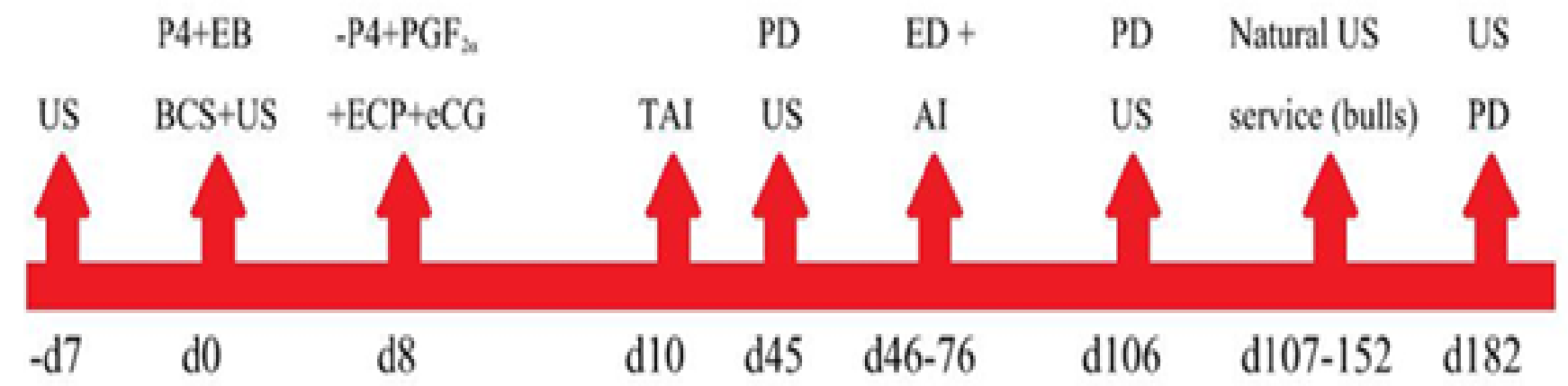

Figure I Hormonal protocol scheme used for the animals conducted in Nellore.

US, ultrasound; P4 (Cronipresmonodosis, 0.558 g progesterone, Biogenesis Bagó, Curitiba-Brazil); EB (Cronibest, I.0mg, IM, Biogenesis Bago); BCS (I-5); PGF2 alpha (Croniben, 0,075mg, IM, Biogenesis Bago); ECP (Estradiol cypionate, 2mg, IM, Zoetis, Sao Paulo, Brazil); eCG (Folligon, 3001 , IM, MSD Animal Health, São Paulo); $\mathrm{dl} 0=\mathrm{TAl}$; $\mathrm{d} 45=$ Pregnancy Diagnosis (PD); from d46 to d76 detection of estrus+conventional Al in repeat breeding animals; ED=Estrus detection; $\mathrm{dI} 07$ to dI 52 heifers were submitted to natural service with bulls; PD occurred at dI 82 .

\section{Results and Discussion}

The results are shown in Table 1. The PR percentages are based on the TAI, conventional AI, and natural breeding results. The protocols used for TAI in Bos indicus heifers using a long-acting P4 intravaginal device followed by the administration of eCG or ECP after device removal have been previously reported by SáFilho, et al. ${ }^{3}$ Claro Junior et al., ${ }^{1}$ Rodrigues et al., ${ }^{11}$ and Silveira et al. ${ }^{5}$ These studies highlighted the importance of hormonal TAI protocols for this category of animal, with an emphasis on animal replacement. Our research group hypothesized that using ECP and eCG in heifers previously "sensitized" by exogenous P4 and PGF2á could have a more positive effect on the PR than other protocols. ${ }^{5}$

The protocol used in this study was administered to 130 prepubertal and 94 pubertal heifers (Table 1). The TAI protocol was able to induce puberty in the heifers, resulting in a PR of $29.2 \%$ in prepubertal and $37.2 \%$ in pubertal heifers. Conventional AI was performed (45days after the BS commenced), and the prepubertal and pubertal PR reached $38.5 \%$ and $58.5 \%$, respectively $(\mathrm{P}<0.05)$ which can be attributed to the protocol. These results demonstrate the importance of using a protocol to achieve such PR percentages in prepubertal heifers, because it is unlikely that these results could be achieved in the BS without the protocol, as previously reported. ${ }^{5}$

The final PRs when TAI, AI and the bull were used in prepubertal and pubertal heifers were $60.7 \%$ and $73.4 \%$ respectively, which only approached a significant difference $(\mathrm{P}>0.06)$. This results indicates that exposure to the hormonal protocol for TAI, is primarily beneficial for prepubertal animals. It is plausible that ECP and eCG were more effective in prepubertal than in pubertal heifers, balancing the ovarian response at the beginning of the BS. ${ }^{11}$ According to Rodrigues et al., ${ }^{11}$ isolated treatments with eCG and/or ECP after 12days of previous exposure to intravaginal $\mathrm{P} 4$ in prepubertal heifers resulted in a higher induction of ovulation when compared to the control group, and the isolated use of ECP performed moderately and did not differ from other treatments.

At the end of the BS, TAI, conventional AI, and natural breeding resulted in a combined PR of $66.0 \%$, and there was no significant difference in the PRs among pubertal and prepubertal heifers. The results of this study are an important finding and could be applied to commercial farms. A study by Claro Junior et al. ${ }^{1}$ in beef cattle in Brazil achieved a PR of $83.7 \%$. The lower PR results observed in our study may have been due to the shorter time that the intravaginal P4 device remained in the heifers in our study compared to that in the study by Claro Junior et al. ${ }^{1}$ ( 8 days versus 12 days). Other possibilities include factors associated with differences in nutrition, BCS, age, and environment conditions. Silveira et al. ${ }^{5}$ administered ECP after P4 removal (d8) in prepubertal and pubertal heifers and achieved PRs of $37.0 \%$ and $49.0 \%$, respectively. This result is higher than the results of the present study (Table 1). We hypothesized that these differences could be attributed to the breed, because Silveira et al. ${ }^{5}$ worked with crossbred (Bos indicus x Bos taurus) heifers. This hypothesis is supported by Rodrigues et al. ${ }^{11}$ who reported that 
heifers that were heavier at the beginning of the protocol, showed the highest percentages of estrous detection and the greatest number of ovulations. Studies by Carvalho et al. ${ }^{12}$ demonstrated that crossbred heifers had a larger dominant follicle (DF) on d8, a larger ovulatory follicle, and a higher DF growth rate compared with pure Bos indicus or Bos taurus heifers. Rodrigues et al. ${ }^{11}$ administered P4 for 12days and ECP and eCG after P4 removal, and reported better reproductive performance in Bos indicus heifers than the other groups that received only eCG or no treatment (control group). SáFilhoet al. ${ }^{3}$ reported that eCG is an important tool to increase follicular growth and ovulation, and the size and function of the subsequent CLs, thus improving the PR.

Table I Pregnancy rate (PR) after application of the hormonal protocol using estradiol cypionate and equine chorionic gonadotropin in Nellore heifers pretreated with an intra vaginal device P4 $(n=224)$

\begin{tabular}{|c|c|c|c|c|c|c|}
\hline Heifers & Number of Animals (\%) & $\begin{array}{l}\text { PR } \\
\text { TAI (\%) }\end{array}$ & $\begin{array}{l}\text { PR } \\
\text { Al (\%) }\end{array}$ & $\begin{array}{l}\text { PR } \\
\text { TAI+AI (\%) }\end{array}$ & PR Bulls (\%) & $\begin{array}{l}\text { PR } \\
\text { TAI +AI + Bull (\%) }\end{array}$ \\
\hline & $130 / 224$ & $38 / 130$ & $12 / 92$ & $50 / 130$ & $29 / 80$ & $79 / 130$ \\
\hline \multicolumn{7}{|c|}{ Prepubertal } \\
\hline & $(58.0)$ & $(29.2)^{\mathrm{a}}$ & $(13.0)^{\mathrm{a}}$ & $(38.5)^{\mathrm{a}}$ & $(36.2)^{\mathrm{a}}$ & $(60.7)^{\mathrm{a}}$ \\
\hline & $94 / 224$ & $35 / 94$ & $20 / 59$ & $55 / 94$ & $14 / 39$ & $69 / 94$ \\
\hline \multicolumn{7}{|l|}{ Pubertal } \\
\hline & $(42.0)$ & $(37.2)^{\mathrm{a}}$ & $(33.9)^{\mathrm{b}}$ & $(58.5)^{\mathrm{b}}$ & $(35.9)^{\mathrm{a}}$ & $(73.4)^{\mathrm{a}}$ \\
\hline
\end{tabular}

PR, pregnancy rate; TAI, timed artificial insemination

Different letters in the same column are statistically significant $(P<0.05)$

\section{Conclusion}

In conclusion, the application of a hormonal protocol such as that utilized in this study is beneficial to heifers because it can hasten the onset of puberty in prepubertal animals and subsequently the PR in pubertal heifers at the beginning of the BS was maximized.

\section{Acknowledgements}

None.

\section{Conflict of interest}

The authors declare they have no conflicts of interest regarding the work presented in this study.

\section{References}

1. Claro Junior I, SáFilho OG, Peres RF, et al. Reproductive performance of prepubertal Bos indicus heifers after progesterone - based treatments. Theriogenology. 2010;74(6):903-911.

2. Souza EM, Milagres JC, Silva MA. Influênciasgenéticas e de meioambientesobre a idadeaoprimeiropartoemrebanhos de Girleiteiro. Rev Bras Zootec. 1995;24:926-935.

3. SáFilho MF, Marques MO, Baruselli OS. Indução de ciclicidade e IATF emnovilhaszebuínas. Brazil: International Symposium of Applied Animal Reproduction; 2010. p. 79-100.

4. Gasser CL, Grum DE, Mussard ML, et al. Induction of precocious puberty in heifers II: Advanced ovarian follicular development. J Anim Sci. 2006;84(8):2042-2049.
5. Silveira EF, Kozicki LE, Segui MS, et al. Comparison of long-term progesterone-based protocol on reproductive performance of prepubertal and pubertal beef heifers. Arch Vet Sci. 2014;19(1):1-6.

6. Sales JNS, Crepaldi GA, Dias LMK, et al. Evaluation of different protocols to induce cyclicity in prepubertal beef heifers. II International Symposium on Animal Biology of Reproduction, Brazil; 2008.

7. Wheaton JE, Lamb GC. Induction of cyclicity in postpartum anestrous beef cows using progesterone, GnRH and estradiol cypionate (ECP). Anim Rep Sci. 2007;102(3-4):208-216.

8. Demeterco D, Henry DD, Mercadante VRG, et al. The effects of intramuscular or intravenous injections of gonadotropin releasing hormone at fixed-time artificial insemination on pregnancy rates of Bos indicus beef cows. Braz Arch Biol Technol. 2014;57(3):361-366.

9. Leitmann NR, Busch DC, Mallory DA. Comparison of long-term CIDR-based protocols to synchronize estrus in beef heifers. Anim Reprod Sci. 2009;114(4):345-355.

10. Peres RF, Claro Junior GI, SáFilho OG, et al. Strategies to improve fertility in Bos indicus postpubertal heifers and nonlactating cows submitted to fixed-time artificial insemination. Theriogenology. 2009;72(5):681689.

11. Rodrigues AD, Peres RFG, Lemes AP, et al. Progesterone-based strategies to induce ovulation in prepubertal Nellore heifers. Theriogenology. 2013;79(1):135-141.

12. Carvalho JB, Carvalho NA, Reis EL, et al. Effect of early luteolysis in progesterone-based timed AI protocols in Bos indicus, Bos indicus x Bos taurus and Bos taurus heifer. Theriogenology. 2008;69(2):176-175. 